\title{
Особливості фізичного розвитку спортсменів як основа диференціації навантажень в тренувальному процесі юних кікбоксерів
}

\author{
Володимир Ашанін \\ Світлана Пятисоцька \\ Яна Жерновнікова \\ Андрій Єфременко \\ Ольга Без'язична \\ Ліана Дугіна
}

Харківська державна академія фізичної культури, Харків, Україна

Мета: визначити показники фізичного розвитку спортсменів групи початкової підготовки з кікбоксингу.

Матеріал і методи: дослідження було проведено на базі ДЮСШ «ХФТІ» м. Харкова. До експерименту було залучено 28 кікбоксерів 10-11 років групи початкової підготовки першого року навчання. У роботі застосовували наступні методи дослідження: теоретичний аналіз та узагальнення наукової літератури, антропометричні вимірювання, методи математичної статистики.

Результати: були проведені візуальні та антропометричні обстеження тіла спортсменів за наступними показниками: довжина і маса тіла, окружність грудної клітини. Також проведено комплексне тестування рухових якостей спортсменів з використанням контрольних вправ, що передбачені державними тестами і нормативами оцінки фізичної підготовленості населення України.

Висновки: у ході дослідження були проведені антропометричні обстеження юнаків 10-11 років, які займаються кікбоксингом, що дозволило встановити особливості будови тіла спортсменів. Були обчислені ваго-зростовий та грудо-зростовий індекси, а також індекс Піньє для визначення соматичного типу спортсменів. В результаті дослідження виявлено, що за індексом Кетле переважна кількість учнів мала рівень фізичного розвитку середній і вище; за індексом пропорційності розвитку грудної клітини - вузьку грудну клітину. За виявленими значенням індексу Пінье встановлено, що більшість кікбоксерів відноситься до астенічного типу конституції. Виявлено важливе значення застосування диференційованого підходу в організації тренувального процесу спортсменів з урахуванням їх соматотипу. Спортсмени 10-11 років різних соматотипів (астенічного, нормостенічного та гіперстенічного) мають суттєві відмінності за показниками розвитку фізичних якостей. Такі результати дослідження експериментально підтвердили необхідність пошуку нових підходів до системи фізичної підготовки спортсменів з урахуванням їх індивідуальних особливостей.

Ключові слова: фізичний розвиток, фізична підготовленість, соматотип, диференційований підхід, спортсмени-кікбоксери, початковий етап підготовки.

\section{Вступ}

Пошук шляхів індивідуалізації і диференціації фізичної підготовки спортсменів в різних видах спорту є предметом дослідження багатьох вчених. На думку науковців, при застосуванні диференційованого підходу тренер має враховувати не тільки статеві й вікові особливості, а й індивідуальні можливості спортсменів [12; 15]. Такий підхід дає змогу кожному спортсмену виконувати навантаження в оптимальному режимі та забезпечує найкращий тренувальний ефект $[1 ; 6]$. Не зважаючи на те, що накопичено численні дані щодо засобів і методів впровадження диференційованого підходу, його практична реалізація вимагає пошуку оптимальних критеріїв диференціації в залежності від виду спорту (або рухової активності) та етапу багаторічної підготовки. Традиційно застосовується статево-віковий критерій диференціації.
Дослідження останніх років дозволили визначити й інші підстави для диференціації навантажень, серед яких виділяють стан здоров'я, біологічний вік, рівень фізичного розвитку, тип статури, рівень фізичної підготовленості. Також додатковими критеріями є властивості нервової системи, тип темпераменту, когнітивні якості [5; 13].

Одним із інформативних критеріїв диференціації в тренувальній діяльності $€$ тип статури спортсмена. Цей критерій має неоднаковий рівень інформативності на різних етапах підготовки та базується на обліку природної різноякісності морфофункціональних властивостей людини. Обґрунтуванням даного твердження служить виявлення того факту, що представники різних типів конституції суттєво відрізняються не тільки за показниками фізичного розвитку, але і по цілому ряду характеристик нейрофізичного статусу, в тому числі за рухови- 
ми можливостями. Тому для раціонального планування навантажень у динаміці тренувального процесу, необхідно знання не тільки особливостей фізичного розвитку і фізичної підготовленості спортсменів, але і конституційних особливостей їх організму [2; 4; 14].

У підготовці спортсменів-одноборців визначення соматотипу має особливе значення не тільки як критерій диференціації навантажень, а й важливий фактор біомеханічної складової реалізації технічних дій. Саме тому визначення та аналіз даного критерію доцільно проводити на всіх етапах багаторічної підготовки, включно $з$ етапом початкової підготовки.

Робота виконана у відповідності до ініціативної теми науково-дослідної роботи «Теоретико-методичні засади диференційованого підходу під час занять фізичною культурою та спортом з використанням інформаційних технологій» (номер державної реєстрації 0120U105014) на 2020 - 2023 рр.

Мета дослідження - визначити показники фізичного розвитку спортсменів групи початкової підготовки з кікбоксингу.

\section{Матеріал і методи дослідження}

Дослідження проводилось на базі Дитячо-юнацької спортивної школи «ХФТ|». В дослідженні брали участь 28 кікбоксерів (хлопці) 10-11 років групи початкової підготовки першого року навчання.
У роботі застосовували наступні методи дослідження: теоретичний аналіз та узагальнення наукової літератури, антропометричні вимірювання, методи математичної статистики.

\section{Результати дослідження}

Дослідження включало візуальну оцінку та антропометричні вимірювання параметрів тіла за наступними показниками: довжина і маса тіла, окружність грудної клітини. Обстеження проводилось 3 метою визначення рівня фізичного розвитку спортсменів та встановлення відповідності даних їх основних антропометричних показників стандартам фізичного розвитку дітей відповідної вікової групи (табл. 1).

Результати антропометричного обстеження свідчать про те, що середньогрупові показники фізичного розвитку спортсменів не мають достовірних відмінностей із стандартними віковими нормами [3; 10]. Це дозволяє вважати фізичний розвиток даної групи спортсменів таким, що відповідає нормі, та планувати тренувальні навантаження у відповідності до вікових стандартів.

Більш детальне обстеження передбачало розрахунок антропометричних індексів - ваго-зростового (Кетле) та грудо-зростового. На основі розрахунку визначили рівень фізичного розвитку спортсменів даної групи (рис. 1).

Таблиця 1

Відповідність антропометричних показників спортсменів групи початкової підготовки з кікбоксингу віковим стандартам фізичного розвитку (10 років, $n=16,11$ років, $n=12)$

\begin{tabular}{|l|c|c|c|c|}
\hline \multicolumn{2}{|c|}{ Антропометричні показники } & \begin{tabular}{c} 
Спортсмени \\
\multicolumn{2}{|c|}{}
\end{tabular} & $\begin{array}{c}\text { Стандарт } \\
\bar{X} \pm m\end{array}$ & $\begin{array}{c}\mathbf{t} \\
\mathbf{( p > 0 , 0 5 )}\end{array}$ \\
\hline \multirow{2}{*}{ Довжина тіла (см) } & 10 років & $144,3 \pm 1,0$ & $142,0 \pm 1,7$ & 1,17 \\
\cline { 2 - 5 } & 11 років & $145,0 \pm 1,2$ & $146,0 \pm 1,5$ & 0,52 \\
\hline \multirow{2}{*}{ Маса тіла (кг) } & 10 років & $33,2 \pm 2,1$ & $32,9 \pm 4,0$ & 0,07 \\
\cline { 2 - 5 } & 11 років & $36,1 \pm 4,1$ & $35,0 \pm 4,1$ & 0,19 \\
\hline \multirow{2}{*}{$\begin{array}{l}\text { Обхват грудної клітини } \\
\text { у спокої (см) }\end{array}$} & 10 років & $69,4 \pm 1,7$ & $68,4 \pm 3,6$ & 0,25 \\
\cline { 2 - 5 } & 11 років & $70,4 \pm 3,4$ & $69,3 \pm 3,9$ & 0,21 \\
\hline
\end{tabular}

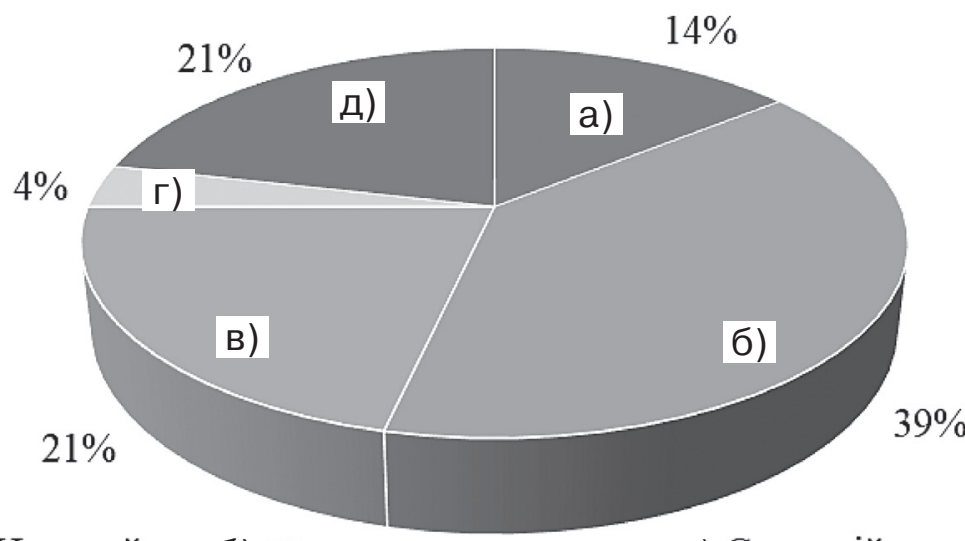

Рис. 1. Відсоткове співвідношення хлопців 10-11 років з різним рівнем фізичного розвитку за індексом Кетле a) Низький

б) Нижче середнього

г) Вище середнього д) Високий в) Середній

тку спортсменів як основа диференціації навантажень в тренувальному процесі юних кікбоксерів»
Слобожанський науково-спортивний вісник, № 1(81), С. 59-65, doi:10.15391/snsv.2021-1.008 


\section{СЛОБОЖАНСЬКИЙ НАУКОВО-СПОРТИВНИЙ ВІСНИК}

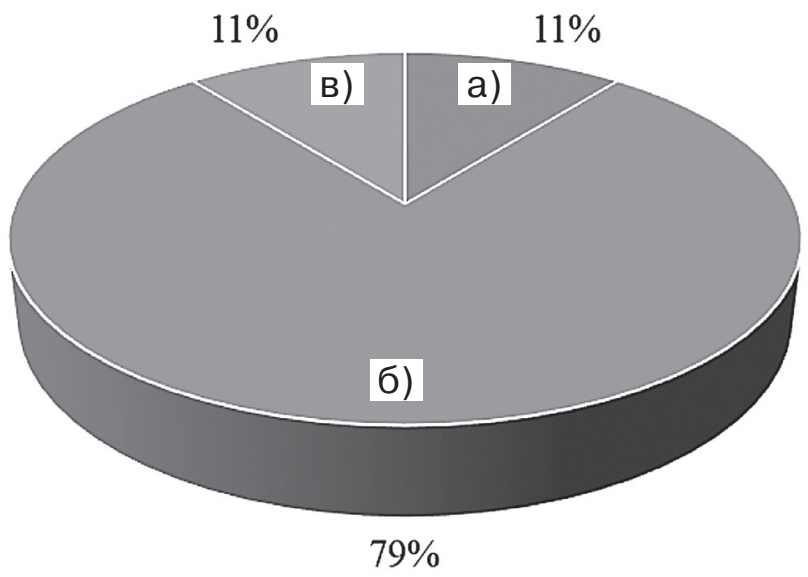

а) Норма б) Вузькогруді в) Широкогруді
Рис. 2.

Відсоткове співвідношення хлопців 10-11 років з різним рівнем пропорційності розвитку грудної клітини за індексом пропорційності розвитку грудної клітини
За індексом Кетле у спортсменів даної групи рівень фізичного розвитку середній і вище виявлено у $46 \%$ обстежуваних. Дані результати свідчать про задовільний рівень фізичного розвитку обстежуваної групи спортсменів початкової підготовки з кікбоксингу.

Розрахунок грудо-зростового індексу дозволив встановити пропорційність розвитку грудної клітини спортсменів та визначити наявність вузької або широкої грудної клітини, або такої, що знаходиться в межах норми (рис. 2). Обстеження показало, що більшість спортсменів (79\%) має вузьку грудну клітину. Ці дані свідчать про недостатню пропорційність розвитку грудної клітини хлопців 10-11 років, що може бути пояснено віковими особливостями дитячого організму, а саме гетерохронністю розвитку поздовжніх та поперечних розмірів тіла. В такій групі спортсменів можна вважати доцільним цілеспрямоване включення вправ для розвитку м'язів плечового поясу та грудних м'язів, як загальнорозвиваючих, так і пов'язаних із специфікою рухової діяльності у кікбоксингу (ударів руками та блоків).

Однією з центральних характеристик при індивідуально-типологічній оцінці розвитку тіла є поняття конституції або соматотипу. У сучасному розумінні конституція - це біологічна характеристика організму, сукупність морфологічних і функціональних ознак, успадкованих і набутих, що визначають особливості реактивності та стійкості організму до несприятливих факторів зовнішнього і внутрішнього середовища. Морфологічний прояв конституції людини - це соматотип, який відображає рівень і гармонійність фізичного розвитку. У той же час він $€$ критерієм стану здоров'я людини і його рухової активності.

Класифікації В. В. Бунака, І. Б. Таланту, В. Г. Штефко і А. Д. Островського, Сіго, Шайю і Мак Оліфа засновані на візуальній оцінці досліджуваного об'єкта і порівнянні цієї оцінки з описовими характеристиками того чи іншого типу статури. До методик, що містять оцінку соматотипу на основі розрахунків за розмірними ознаками, відносяться розробки Б. А. Никитюка, С. Шелдона, Б. Хіта - Л. Картера. [9].

Для уникнення суб'єктивізму під час визначення індивідуального конституційного типу спортсмена ми застосували соматометричний метод, який полягає у вимірюванні довжини тіла (см), маси тіла (кг) та окружності грудної клітини (см).

Ці параметри були використані для обчислення індексу Піньє за формулою:

$$
I \Pi=L-(M+\text { ОГКвид. }),
$$

де L - довжина тіла (см), M - маса тіла (кг); ОГКвид. окружність грудної клітини на видиху (см).

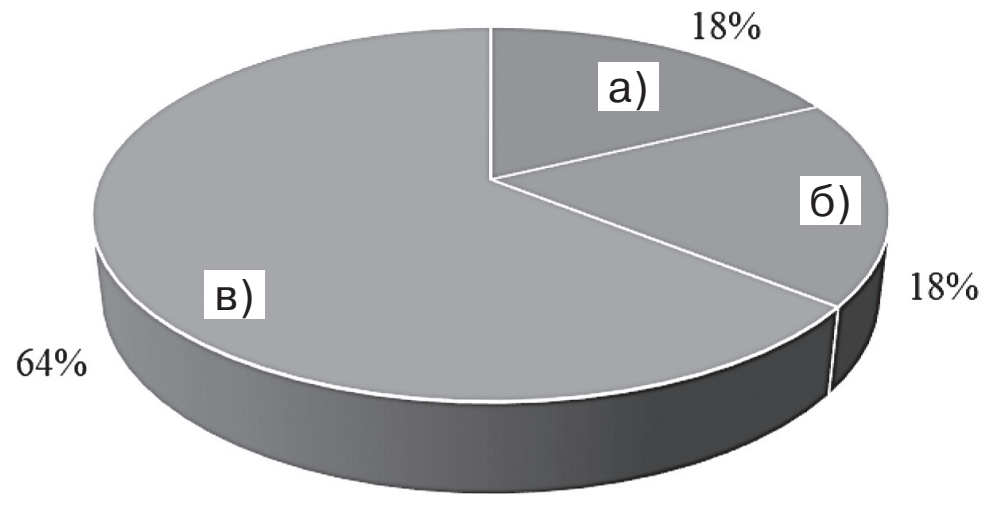

a) Гіперстенік б) Нормостенік в) Астенік
Рис. 3.

Відсоткове співвідношення хлопців 10-11 років з різним рівнем міцності статури за індексом Піньє 
Індекс Пін'є, що складає більше 30 одиниць, свідчить про астенічний (гіпостенічний) конституційний тип, менше 10 - про гіперстенічний. Індекс у межах від 10 до 30 одиниць відповідає нормостенічному конституційному типу. Розрахунок індексу Пін'є дав змогу оцінити правильність встановлення конституційного типу спортсменів за попереднім визначенням за допомогою соматоскопічного методу [9].

Аналізуючи показник індексу Піньє, було встановлено, що більша кількість хлопців 10-11 років, які займаються кікбоксингом має астенічний тип статури, що відповідає слабкій статурі (рис. 3). Діти зі слабкою статурою потребують особливо ретельного підбору навантажень в навчально-тренувальному процесі, а також постійного контролю з боку тренера. Тому тренувальні заняття з такими учнями необхідно планувати на основі диференційованого підходу з урахуванням особливостей їх фізичного розвитку.

В ході дослідження було проведено комплексне тестування рухових якостей спортсменів. Рівень загальної фізичної підготовленості оцінювався за результатами контрольних вправ, що передбачені державними тестами і нормативами оцінки фізичної підготовленості населення України [11]. Результати тестування фізичної підготовленості були проаналізовані з урахуванням соматичного типу спортсменів, що був визначений раніше (табл. 2).

Аналіз результатів тестування дозволив встановити, що спортсмени із нормостенічним конституційним типом мають достовірно більші результати у вправах, які вимагають прояву витривалості (на рівні $p<0,05$ ). Спортсмени із гіперстенічним типом показали кращі результати у вправах, що вимагають переважного прояву силових якостей. Слід зазначити, що дані відмінності у порівнянні з результатами спортсменів інших соматотипів не мають достовірного характеру $(p>0,05)$. Спортсмени із астенічним типом були найбільш успішні у вправах, що вимагають прояву гнучкості $(p>0,05)$ та бистроти $(\mathrm{p}<0,05)$.

Отримані результати рухової підготовленості спортсменів різних соматотипів відображають відхилення результатів астеніків і гіперстеніків від середньо- групових по цілому ряду контрольних вправ. Зокрема, гіперстеніки мають результати нижче середньогрупових у тестах: нахил тулуба вперед із положення сидячи, біг на 30 м та човниковий біг 449 м. Схожі особливості проявляють і астеніки у тестах: згинання і розгинання рук в упорі лежачи, нахил тулуба вперед із положення сидячи, човниковий біг 449 м. У той же час нормостеніки показують середній і вище середнього рівень розвитку всіх рухових здібностей по відношенню до середньогрупового показника.

\section{Висновки / Дискусія}

В результаті проведеного аналізу визначено основні морфологічні показники спортсменів 10-11 років, які займаються кікбоксінгом. Тотальні розміри тіла обстежуваних кікбоксерів суттєво не відрізняються від ваги та зросту умовної середньостатистичної дитини відповідної вікової групи.

Були обчислені індекс Кетле та індекс пропорційності розвитку грудної клітини. Встановлено, що за індексом Кетле переважна кількість учнів мали рівень фізичного розвитку середній і вище; за індексом пропорційності розвитку грудної клітини - вузьку грудну клітину. За виявленими значенням індексу Пінье можемо зробити висновок, що більшість кікбоксерів відносяться до астенічного типу конституції.

В результаті дослідження було виявлено, що спортсмени 10-11 років групи початкової підготовки з кікбоксингу трьох соматотипів (астеніки, нормостеніки, гіперстеніки) мають суттєві відмінності за показниками фізичної підготовленості, а також переважного розвитку фізичних якостей. Результати дослідження експериментально підтвердили необхідність пошуку нових підходів до вдосконалення системи фізичної підготовки спортсменів в кікбоксингу з урахуванням їх індивідуальних особливостей.

Перспективи подальших досліджень полягають у розробці диференційованого підходу до визначення обсягу й інтенсивності навантажень у тренувальному процесі кікбоксерів на початковому етапі підготовки 3 урахуванням рівня фізичного розвитку та конституційного типу.

Таблиця 2

Показники фізичної підготовленості спортсменів групи початкової підготовки з кікбоксингу різних соматотипів

\begin{tabular}{|l|c|c|c|}
\hline \multicolumn{1}{|c|}{ Показники } & \multicolumn{1}{|c|}{$\begin{array}{c}\text { Астенік } \\
\text { (n=18) }\end{array}$} & $\begin{array}{c}\text { Нормостенік } \\
(\mathbf{n = 5 )}\end{array}$ & $\begin{array}{c}\text { Гіперстенік } \\
\text { (n=5) }\end{array}$ \\
\hline $\begin{array}{l}\text { Згинання і розгинання рук в } \\
\text { упорі лежачи (разів) }\end{array}$ & $8,5 \pm 0,8$ & $11,4 \pm 5,2$ & $14,2 \pm 3,8$ \\
\hline $\begin{array}{l}\text { Підтягування у висі лежачи } \\
\text { (разів) }\end{array}$ & $1,6 \pm 1,2$ & $2,5 \pm 0,7$ & $3,8 \pm 0,9$ \\
\hline $\begin{array}{l}\text { Нахил тулуба вперед із } \\
\text { положення сидячи (см) }\end{array}$ & $4,3 \pm 0,7$ & $2,0 \pm 1,3$ & $2,4 \pm 0,9$ \\
\hline Біг на 30 м (с) & $5,8 \pm 0,1$ & $6,6 \pm 0,2$ & $6,0 \pm 0,2$ \\
\hline $\begin{array}{l}\text { Рівномірний біг без урахування } \\
\text { часу (м) }\end{array}$ & $720,0 \pm 48,9$ & $933,3 \pm 36,2$ & $840,0 \pm 97,9$ \\
\hline Човниковий біг 4×9 м (с) & $11,8 \pm 0,1$ & $12,2 \pm 0,3$ & $11,9 \pm 0,3$ \\
\hline
\end{tabular}


Конфлікт інтересів. Автори заявляють, що немає конфлікту інтересів, який може сприйматись таким, що завдасть шкоди неупередженості статті.

Джерела фінансування. Ця стаття не отримала фінансової підтримки від державної, громадської або комерційної організації.

\section{Список посилань}

1. Арефьєв В. Г. (2017), «Педагогічні технології реалізації диференційованого фізичного виховання учнів основної школи", Науковий часопис НПУ імені МП Драгоманова. Серія 15: Науково-педагогічні проблеми фізичної культури (фізична культура і спорт), №3 (84), С. 29-33.

2. Бугайов Є. В., Джим В. Ю. (2017), «Антропометричні особливості юних важкоатлетів 10-12 років та юнаків того ж віку, які не займаються спортом", Науковий часопис НПУ імені МП Драгоманова. Серія 15: Науково-педагогічні проблеми фізичної культури (Фізична культура і спорт), №5 (87), С. 21-24.

3. Володченко А. В. (2017), «Особенности физического развития спортсменов кик-боксинга разного уровня подготовки», Науковий часопис НПУ імені МП Драгоманова. Серія 15: Науково-педагогічні проблеми фізичної культури (фізична культура і спорт), № 5 (87), С. 24-28.

4. Жерновникова Я. В. (2015), «Определение возрастных изменений антропометрических показателей у школьников 5-7 классов с использованием компьютерной программы «Здоровье школьника»», Вісник Чернігівського національного педагогічного університету імені Т.Г. Шевченка. Серія: Педагогічні науки. Фізичне виховання та спорт, № 129, С. $136-140$.

5. Жерновнікова Я. В. (2019), Методика розвитку рухових якостей учнів основної школи на уроках фізичної культури 3 урахуванням рівнів біологічного розвитку: автореф. дис. на здобуття наук. ступ. канд. пед. наук: спец. 13.00.02, Харків, 20 с.

6. Жерновнікова Я.В. (2018), «Формування рухових якостей учнів основної школи: диференціація фізичних навантажень та урахування рівнів біологічного розвитку», Вісник Запорізького національного університету. Педагогічні науки, № 1(30), С. 17-22.

7. Жерновнікова Я. В., Пятисоцька С. С. (2017), «Особливості впровадження диференційованого підходу у процес фізичного виховання з метою збереження здоров'я школярів», Фізична реабілітація та рекреаційно-оздоровчі технології, № 2, С. $54-59$.

8. Кулик А. Є. (2011), «Диференційований підхід до організації занять з фізичного виховання школярів з урахуванням їх соматипів», Сучасні оздоровчо-реабілітаційні технології, № 6, С. 56-61.

9. Неведомська Є. О., Михайловська А. П. (2014), «Про що розповість педагогу конституція тіла студента», Освітологічний дискурс, № 1 (5). С. 168-181.

10. Сердюк А. М. (2010), Стандарти для оцінки фізичного розвитку школярів, Випуск 3, Київ: Казка.

11. Фізична культура в школі: навч. програма для 1-4, 5-9 класів загальноосвіт. навч. закл., (2013), Київ: Літера Лтд.

12. Aghyppo O., Dorofeeva T., Puhach Y., Artem'yeva G., Nechytailo M., Druz V. (2015), «Norm, standards and tests in the structure of creation of monitoring of physical development, physical fitness and physical state», Slobozhanskyi herald of science and sport, № 5 (49), pp. 13-23.

13. Ashanin V., Druz V., Pyatisotskaya S., Zhernovnikova Y., Aleksieieva I., Aleksenko Y., Yefremenko A., \& Pilipko O. (2018), «Methods for determining the biological age of different children», Journal of Physical Education and Sport, 18, pp. 1845-1849.

14. Drywien M., Frackiewicz J., Gornicka M., Wielgosz J., Sobolewska A., \& Kulik S. (2016), «Influence of the somatotype on intake of energy and nutrients in women», Anthropological Notebooks, 22(3), pp.147-157.

15. Shesterova L., Yefremenko A., Nizhevskaya T., Pugach Y., Druz V., Ashanin V., Pyatisotskaya S., Miroshnichenko V. (2017), "Modern methods of increasing working capacity and recovery processes of sportsmen in the system of organization of sports training", Journal of Physical Education and Sport, 17, pp. 2129-2134.

Стаття надійшла до редакції: 25.01.2021 р.

Опубліковано: 22.02.2021 p.

Аннотация. Владимир Ашанин, Светлана Пятисоцкая, Яна Жерновникова, Андрей Ефременко, Ольга Безъязычная, Лиана Дугина. Особенности физического развития спортсменов как основа дифференциации нагрузок в тренировочном процессе юных кикбоксеров. Цель: определить показатели физического развития спортсменов группы начальной подготовки по кикбоксингу. Материал и методы: исследование было проведено на базе ДЮСШ «ХФТИ» г. Харьков. К эксперименту было привлечено 28 кикбоксеров 10-11 лет группы начальной подготовки первого года обучения. В работе применяли следующие методы исследования: теоретический анализ и обобщение научной литературы, антропометрические измерения, методы математической статистики. Результаты: были проведены визуальные и антропометрические обследования тела спортсменов по следующим показателям: длина и масса тела, окружность грудной клетки. Также проведено комплексное тестирование двигательных качеств спортсменов с использованием контрольных упражнений, предусмотренные государственными тестами и нормативами оценки физической подготовленности населения Украины. Выводы: в ходе исследования были проведены антропометрические обследования юношей 10-11 лет, которые занимаются кикбоксингом, что позволило установить особенности строения тела спортсменов. Были вычислены весо-ростовой и грудо-ростовой индексы, а также индекс Пинье для определения соматического типа спортсменов. В результате исследования выявлено, что по индексу Кетле большее количество учеников имели уровень физического развития средней и выше; по индексу пропорциональности развития грудной клетки - узкую грудную клетку. По выявленным значением индекса пень установлено, что большинство кикбоксеров относятся к астеническому типу конституции. Выявлено важное значение применения дифференцированного подхода в организации тренировочного процесса спортсменов с учетом их соматотипа. Спортсмены 10-11 лет разных соматотипов (астенического, нормостенического и гиперстенического) имеют существенные различия по показателям развития физических качеств. Такие результаты исследования экспериментально подтвердили необходимость поиска новых подходов к системе физической подготовки спортсменов с учетом их индивидуальных особенностей.

Ключевые слова: физическое развитие, физическая подготовленность, соматотип, дифференцированный подход, спортсмены-кикбоксеры, начальный этап подготовки. 


\begin{abstract}
Volodymyr Ashanin, Svitlana Pyatisotska, Yana Zhernovnikova, Andrii Yefremenko, Olha Beziazychna, Liana Duhina. Features of physical development of athletes as the basis for differentiation of loads in the training process of young kickboxers. Purpose: to determine the indicators of physical development of athletes of the group of initial training in kickboxing. Material and methods: the research was carried out on the basis of the Children's and Youth Sports School "KIPT", Kharkov. 28 kickboxers of 10-11 years old group of initial training of the first year of study were involved in the experiment. The following research methods were used in the work: theoretical analysis and generalization of scientific literature, anthropometric measurements, methods of mathematical statistics. Results: visual and anthropometric examinations of the athletes' bodies were carried out according to the following indicators: body length and weight, chest circumference. Also, complex testing of athletes' motor qualities was carried out using control exercises provided for by state tests and standards for assessing the physical fitness of the population of Ukraine. Conclusions: in the course of the study, anthropometric examinations of 10-11 years old youths who are engaged in kickboxing were carried out, which made it possible to establish the features of the body structure of athletes body mass and chest height indices were calculated, as well as the Pignet index to determine the somatic type of athletes. As a result of the study, it was revealed that according to the Quetelet index, the overwhelming number of students had a level of physical development of average and higher; according to the index of proportionality of the development of the chest - a narrow chest. According to the revealed value of the Pignet index, it was established that the majority of kickboxers belong to the asthenic type of constitution. The importance of using a differentiated approach in organizing the training process of athletes, taking into account their somatotype, was revealed. Athletes 10-11 years old of different somatotypes (asthenic, normosthenic and hypersthenic) have significant differences in terms of the development of physical qualities. These are the results of the study experimentally confirmed the need to search for new approaches to the system of physical training of athletes taking into account their individual characteristics.
\end{abstract}

Keywords: physical development, physical fitness, somatotype, differentiated approach, kickboxers, initial stage of training.

\title{
References
}

1. Arefiev, V. G. (2017), «Pedagogical technologies for the implementation of differentiated physical education of primary school students", Naukovyi chasopys NPU imeni MP Dragomanova. Seriia 15: Naukovo-pedagogichni problem fizychnoyi kultury (fizychna kultura I sport), No.3 (84), pp. 29-33. (in Ukr.).

2. Bugaiov, Y. V., Dzhym, V. Y. (2017), «Anthropometric features of young 10-12 years old weightlifters and young men of the same age who do not play sports», Naukovyi chasopys NPU imeni MP Dragomanova. Seriia 15: Naukovo-pedagogichni problem fizychnoyi kultury (fizychna kultura I sport), No.5 (87), pp. 21-24. (in Ukr.).

3. Volodchenko, A. V. (2017), «Features of physical development of kick-boxing athletes of different levels of training», Naukovyi chasopys NPU imeni MP Dragomanova. Seriia 15: Naukovo-pedagogichni problem fizychnoyi kultury (fizychna kultura I sport), No.5 (87), pp. 24-28. (in Ukr.).

4. Zhernovikova, Y. V. (2015), «Determination of age-related changes in anthropometric indicators in schoolchildren of 5-7 grades using the computer program «Schoolchildren's Health», Visnyk Chernihivskoho natsionalnogo pedahohichnoho universytetu T.H. Shevchenka. Seriya: Pedahohichni nauky. Fizychne vykhovannia ta sport, No. 129, pp. 136-140. (in Ukr.).

5. Zhernovikova, Y. V. (2019), Metodyka rozvytku rukhovykh iakostei uchniv osnovnoyi shkoly na urokakh fizychnoyi kultury z urakhuvanniam rivniv biolohichnoho rozvytku [Methods of developing motor skills of primary school students in physical education classes, taking into account the levels of biological development]: avtoref. dys. na zdobuttia nauk. stup. kand. ped. nauk: spets. 13.00.02, Kharkiv, 20 p. (in Ukr.).

6. Zhernovikova, Y. V. (2018), «Formation of motor qualities of primary school students: differentiation of physical activity and taking into account the levels of biological development», Visnyk Zaporizkoho natsionalnoho universytetu. Pedahohichni nauky, No. 1(30), pp. 17-22. (in Ukr.).

7. Zhernovikova, Y. V., Piatysotska, S. S. (2017), «Peculiar fatures of the introduction of a differentiated approach in the process of physical education in order to preserve the health of students», Fizychna reabilitatsiia ta rekreatsiyno-ozdorovchi tekhnolohii, No. 2, pp. 54-59. (in Ukr.).

8. Kulyk, A. Y. (2011), «Differentiated approach to the organization of classes on physical education of schoolchildren taking into account their somatypes», Suchasni ozdorovcho-reabilitatsiyni tekhnolohii, No. 6, pp. 56-61. (in Ukr.).

9. Nevedomska, Y. O., Mykhailovska, A. P. (2014), «What will the constitution of the student's body tell the teacher», Osvitolohichnyi dyskurs, No. 1 (5), pp. 168-181. (in Ukr.).

10. Serdiuk, A. M. (2010), Standarty dlia otsinky fizychnoho rozvytku shkoliariv [Standards for assessing the physical development of students], Vypusk 3, Kazka, Kyiv. (in Ukr.).

11. Fizychna kultura v shkoli: navch. Prohrama dlia 1-4, 5-9 klasiv zahalnoosvit. navch. zakl. [Physical education at school: curriculum for 1-4, 5-9 grades of secondary schools], (2013), Kyiv Litera LTD/ (in Ukr.).

12. Azhyppo, O., Dorofeeva, T., Puhach, Y., Artemieva, G., Nechytailo, M., Druz, V. (2015), «Norm, standards and tests in the structure of creation of monitoring of physical development, physical fitness and physical state», Slobozhanskyi herald of science and sport, № 5 (49), pp. 13-23. (in Eng.).

13. Ashanin, V., Druz, V., Piatysotskaya, S., Zhernovnikova, Y., Aleksieieva, I., Aleksenko, Y., Yefremenko, A., \& Pilipko, O. (2018), «Methods for determining the biological age of different children», Journal of Physical Education and Sport, 18, pp. 18451849. (in Eng.).

14. Drywien, M., Frackiewicz, J., Gornicka, M., Wielgosz, J., Sobolewska, A., \& Kulik, S. (2016), «Influence of the somatotype on intake of energy and nutrients in women», Anthropological Notebooks, 22(3), pp.147-157. (in Eng.).

15. Shesterova, L., Yefremenko, A., Nizhevskaya, T., Pugach, Y., Druz, V., Ashanin, V., Piatysotskaya, S., Miroshnichenko, V. (2017), "Modern methods of increasing working capacity and recovery processes of sportsmen in the system of organization of sports training", Journal of Physical Education and Sport, 17, pp. 2129-2134. (in Eng.).

Received: 25.01.2021.

Published: 22.02.2021. 


\section{СЛОБОЖАНСЬКИЙ НАУКОВО-СПОРТИВНИЙ ВІСНИК}

\section{Відомості про авторів / Information about the Authors}

Ашанін Володимир Семенович: к.фіз.-мат.н., професор; Харківська державна академія фізичної культури: вул. Клочківська 99, Харків, 61058, Україна.

Ашанин Владимир Семенович: к. физ. -мат.н., профессор; Харьковская государственная академия физической культуры: ул. Клочковская 99, г. Харьков, 61058, Украина.

Volodymyr Ashanin: PhD (Physics-Mathematics), Professor; Kharkiv State Academy of Physical Culture: Klochkivska str. 99, Kharkiv, 61058, Ukraine.

ORCID.ORG/0000-0002-4705-9339

E-mail: ashaninvladimir47@gmail.com

Пятисоцька Світлана Сергї̈вна: к.фіз. вих.; Харківська державна академія фізичної культури: вул. Клочківська 99, м. Харків, 61058, Україна.

Пятисоцкая Светлана Сергеевна: к.физ.восп.; Харьковская государственная академия физической культуры: ул. Клочковская 99, г. Харьков, 61058, Украина.

Svitlana Pyatisotska: PhD (Physical education and Sport); Kharkov State Academy of Physical Culture: Klochkovska Street 99 , Kharkov, 61058, Ukraine.

ORCID.ORG/0000-0002-2246-1444

E-mail: skharchenko@rambler.ru

Жерновнікова Яна Вікторівна: к. пед. н., старший викладач; Харківська державна академія фізичної культури, вул. Клочківська,99, м. Харків, 61058, Україна.

Жерновникова Яна Викторовна: к. пед. н., старший преподаватель; Харьковская государственная академия физической культуры, ул. Клочковская, 99, г. Харьков, 61058, Украина.

Yana Zhernovnikova: PhD (Pedagogical Science), senior lecturer; Kharkiv State Academy of Physical Culture: Klochkivska str. 99, Kharkiv,61058, Ukraine.

\section{ORCID.ORG/0000-0002-5574-8652}

E-mail: zhernovnicova@gmail.com

Єфременко Андрій Миколайович: к. фіз. вих.; Харківська державна академія фізичної культури: Україна, м. Харків, вул. Клочківська, 99.

Ефременко Андрей Николаевич: к. физ. восп.; Харьковская государственная академия физической культуры: ул. Клочковская 99, г. Харьков, 61058, Украина.

Andrii Yefremenko: PhD (Physical Education and Sport); Kharkiv State Academy of Physical Culture: Klochkovskaya str. 99, Kharkiv, 61058, Ukraine.

ORCID.ORG/0000-0003-0924-0281

E-mail: ukrnac@ukr.net

Без'язична Ольга Володимирівна: старший викладач; Харківська державна академія фізичної культури, вул. Клочківська,99, м. Харків, 61058, Україна.

Безъязычная Ольга Владимировна: старший преподаватель; Харьковская государственная академия физической культуры, ул. Клочковская, 99, г. Харьков, 61058, Украина.

Olha Beziazychna: senior lecturer; Kharkiv State Academy of Physical Culture: Klochkivska str. 99, Kharkiv,61058, Ukraine.

ORCID.ORG/0000-0001-9987-6405

E-mail: obezyazychnaya@gmail.com

Дугіна Ліана Вячеславівна: к.фіз.вих., доцент; Харківська державна академія фізичної культури: вул. Клочківська, 99, м. Харків, 61058, Україна.

Дугина Лиана Вячеславовна: к.физ.восп., доцент; Харьковская государственная академия физической культуры: ул. Клочковская, 99, г.Харьков, 61058, Украина.

Liana Duhina: PhD (Physical Education and Sport), Associate Professor; Kharkiv State Academy of Physical Culture: Klochkivska str. 99, Kharkiv, 61058, Ukraine.

ORCID.ORG/0000-0002-4278-4830

E-mail: lianadugina@gmail.com 